\title{
STUDIES ON GYNANDROMORPHS INDUCED WITH THE CLARET-NONDISIUNCTIONAL MUTATION OF DROSOPHILA MELANOGASTER. AN APPROACH TO THE TIMING OF CHROMOSOME LOSS IN CLEAVAGE MITOSES
}

\author{
PETTER PORTIN \\ Department of Genetics, University of Turku, SF-20500 Turku 50, Finiand
}

Received 26.iv.78

\section{SUMmaRY}

By means of analysis of 183 gynandromorphs induced with the claretnondisjunctional mutation of Drosophila melanogaster it was found that the mean proportion of male cuticle in these gynandromorphs was 42 per cent with a standard deviation of 22 per cent. Gynandromorphs arise in eggs laid by homozygous claret-nondisjunctional females as a consequence of loss of the maternal $\mathrm{X}$ chromosome in early cleavage mitoses. The distribution of gynandromorphs according to the proportion of male cuticle compared to the corresponding normal distribution suggested that multiple losses of the $\mathrm{X}$ chromosome are rare, and probably absent. A comparison of the observed distribution with a theoretical normal distribution expected on the assumption of first cleavage division loss of the $\mathrm{X}$ chromosome suggested that two-thirds of the gynandromorphs arise as a consequence of first division loss, whereas onethird arise as a consequence of $\mathrm{X}$ chromosome loss in a later division. Some 21 per cent of the gynandromorphs were haplo-4 mosaics also. In about threequarters of these the loss of the 4th chromosome had occurred in the same division as the loss of the $\mathrm{X}$ chromosome and, with one exception, the 4 th chromosome was lost in the same cell line as the $\mathrm{X}$ chromosome. In about one-quarter of the haplo- 4 mosaic gynandromorphs the 4th chromosome was lost in a different division than the $\mathrm{X}$ chromosome. In these cases the loss of the 4th chromosome seems to be equally frequent in the XX and XO cell lines. Some of the gynandromorphs were fertile as females. In these gynandromorphic females meiosis occurs autonomously.

\section{INTRODUCTION}

GYNANDROMORPHS are genetically mosaic individuals, partly female (gyne) and partly male (aner). In Drosophila melanogaster there are several methods by which gynandromorphs can be induced (see Hall et al., 1976, for a review). One of these methods is the use of the X-ray induced claretnondisjunctional $\left(c a^{n d}, 3-100 \cdot 7\right)$ mutation discovered by Lewis and Gencarella (1952). It is homologous with the claret mutation of Drosophila simulans analysed by Sturtevant (1929). In both species the mutation causes nondisjunction of homologues in the first meiotic division, and loss of chromosomes in the second meiotic division of homozygous females, while meiosis in homozygous males is normal. Furthermore there may be loss of maternal chromosomes in early cleavage divisions of eggs laid by homozygous females, with the paternal chromosomes remaining unaffected (Davis, 1969). A loss of the maternal $\mathrm{X}$ chromosome in an early division of a XX zygote generates populations of XX (female) and $\mathrm{XO}$ (male) cells thus giving rise to a gynandromorphic fly. 
The aim of the present study was to investigate chromosome loss during early divisions of the eggs laid by homozygous claret-nondisjunctional females. This was done by analysing regular gynandromorphs found in the progeny of $c a^{n d}$ females. The results indicate that behaviour of chromosomes in the cleavage mitoses of eggs of $c a^{n d}$ females of Drosophila melanogaster is virtually identical with the chromosomes in the eggs of claret females of $D$. simulans. This is further evidence for the homology of the two mutations. Models of the timing of the $\mathrm{X}$ chromosome loss in the cleavage mitoses will be given.

\section{Material AND methods}

\section{(i) Production of gynandromorphs}

Lewis and Gencarella (1952) reported that 5.4 per cent of the progeny of females homozygous for $c a^{n d}$ were gynandromorphs. In Hinton's material (published by Davis, 1969) 4.7 per cent of the progeny of $c a^{n d}$ females were gynandromorphs. Of these 0.6 per cent were exceptional ( $X X Y-X Y$ ), and 4.1 per cent regular ( $\mathrm{XX}-\mathrm{XO}$ ) gynandromorphs. Davis (1969) observed 3.96 per cent regular, and 0.42 per cent exceptional gynandromorphs in the progeny of $c a^{\text {nd }}$ females. In the present study a total of 183 regular gynandromorphs were collected from the progeny of two crosses. In the first cross $+1+; c a^{n d} / c a^{n d}$ females were crossed to $y w s n^{3} / \Upsilon ;+1+$ males. In the second cross $+1+; c a^{n d} / c a^{n d}$ females were crossed to $y w / x$; $+1+$ males. The first cross yielded 82 , and the second cross 101 regular gynandromorphs. These were identified as mosaic individuals: the XX cuticle of wild type, and the recessive paternal markers (yellow, y $1-0 \cdot 0$; white $w 1-1 \cdot 5$, and singed, $s n^{3} 1-21 \cdot 0$ ) expressed in the XO cuticle. The obviously non-gynandromorphs were discarded. The autonomous expression of yellow, white, and singed makes it possible to distinguish accurately between the female and male parts in the gynandromorphs. Ninety-four gynandromorphs from the second cross were inspected for 4th-chromosome mosaicism also. Haplo-4 cuticle has a typical Minute phenotype characterised by diminished bristles (Lindsley and Grell, 1968), while diplo-4 and triplo-4 tissues are not Minute. This was not done for the gynandromorphs from the first cross since the singed character of bristles makes it difficult to distinguish Minute and not Minute.

\section{(ii) Estimation of the amount of the male cuticle in the gynandromorphs}

A picture of each gynandromorph was drawn on a ready printed scheme (fig. 1). In most cases one can characterise the gynandromorph specimen by a single schematic drawing indicating female and male parts. The amount of male cuticle was measured (from the picture with the aid of transparent grid-paper of $\frac{1}{4} \mathrm{~cm}^{2}$ ) and expressed as percentage of the whole surface. The wings and legs were not included in the measurements. The frequency of 30 structures listed in table 2 exhibiting male cuticle was also tabulated from the pictures, as well as the number of male structures (parts) in each specimen. Since each of these structures is bilateral, the highest number of male parts was 60 , and the number of sides scored $2 \times 183=366$. 


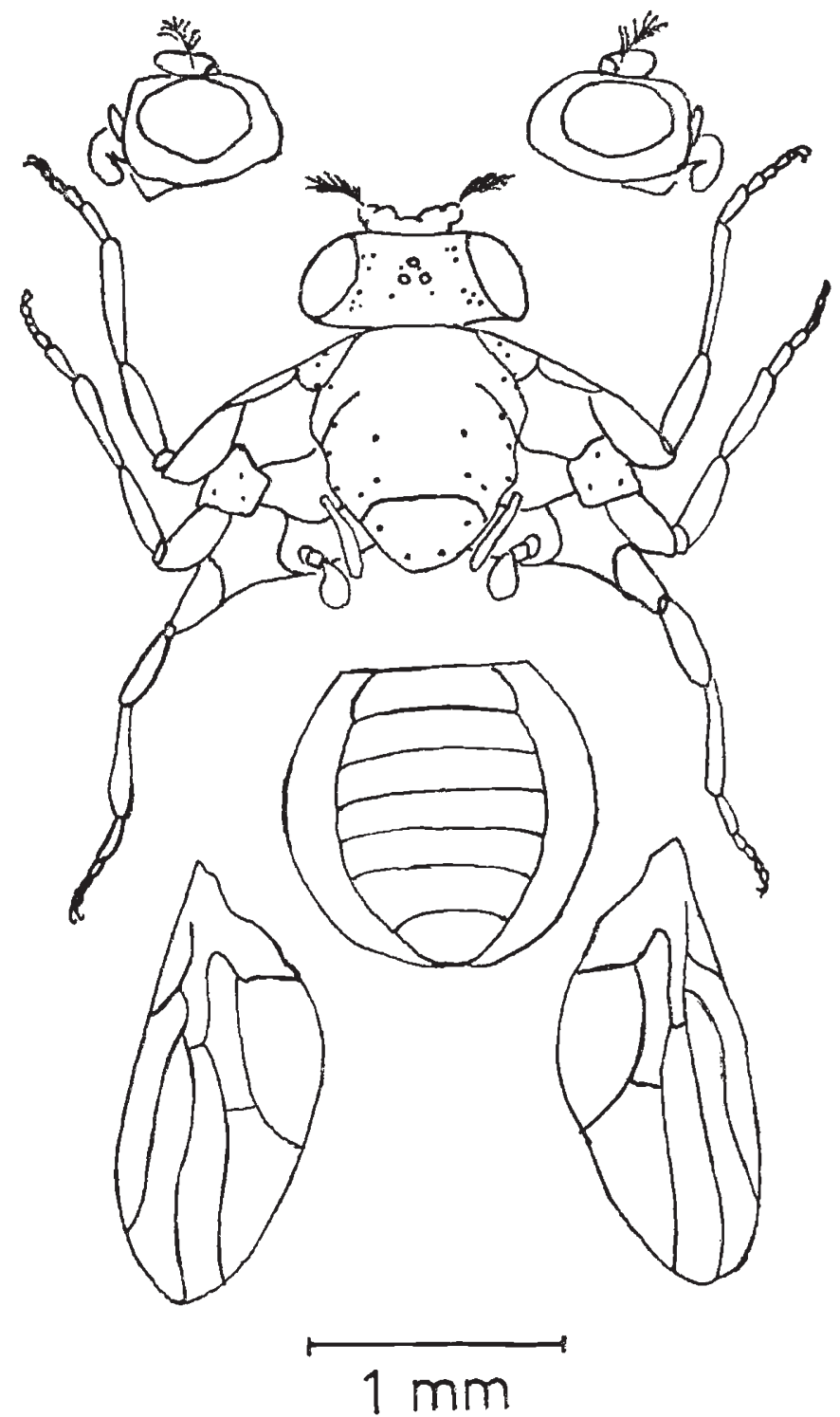

FIG. 1.-Scheme of Drosophila melanogaster used to characterize the gynandromorphs. In the figure the wings are in a smaller scale than the rest of the body.

In case a given structure was mosaic, it was counted as half-male-halffemale.

(iii) Technical details

Because of the low fertility of $c a^{\text {nd }}$ females, the crosses were made with 10 females to a culture. Virgin females were put with 10 males in a $50 \mathrm{ml}$ culture bottle containing standard Drosophila medium (consisting of semolina, syrup, and agar-agar), and kept there for 4 days. Thereafter the parent flies were transferred to fresh culture bottle for 2 more days. Thus 
progeny from the first 6 days was collected. The progeny was raised at $25^{\circ} \mathrm{C}$.

\section{(iv) Statistical methods}

The methods used to compare observed distribution with a normal distribution can be found in Snedecor and Cochran (1967, pp. 84-85) (drawing of the normal curve), and in Bonnier and Tedin (1940, pp. 254261) (Chi-square test of normality of the distribution).

\section{Results}

(i) The proportion of male cuticle in the gynandromorphs

The distribution of regular gynandromorphs according to the proportion of the male cuticle from the two crosses is presented in table 1. In the first

\section{TABLE 1}

The distribution of the proportion of the male cuticle in regular gynandromorphs induced by the claretnondisjunctional mutation

\begin{tabular}{|c|c|c|c|}
\hline \multirow{2}{*}{$\begin{array}{c}\text { Proportion of } \\
\text { male cuticle }(\%)\end{array}$} & \multicolumn{3}{|c|}{ Number of gynandromorphs } \\
\hline & Exp. I & Exp. II & Total \\
\hline $0-20$ & 16 & 16 & 32 \\
\hline $21-40$ & 26 & 33 & 59 \\
\hline $41-60$ & 31 & 27 & 58 \\
\hline $61-80$ & 5 & 17 & 22 \\
\hline $81-100$ & 4 & 8 & 12 \\
\hline Total & 82 & 101 & 183 \\
\hline Mean $^{1} \%$ & $39 \cdot 68$ & $43 \cdot 27$ & $41 \cdot 67$ \\
\hline S.D. $1 \%$ & $20 \cdot 36$ & $24 \cdot 08$ & $22 \cdot 51$ \\
\hline
\end{tabular}

${ }^{1}$ The mean and the standard deviation were calculated from the unclassified material.

cross the mean proportion of male cuticle was $39 \cdot 68 \pm$ S.D. $20 \cdot 36$ per cent. In the second cross the corresponding value was $43 \cdot 27 \pm 24.08$ per cent. The frequency-distributions of the gynandromorphs of the two crosses did not differ significantly $\left(\chi_{4}^{2}=7 \cdot 41\right)$. In the pooled material the mean proportion of male cuticle was $41 \cdot 67 \pm$ S.D. $22 \cdot 51$ per cent.

The frequency of different structures of the fly being male is shown in table 2. The mean frequency of maleness was 41.91 per cent which is very close to the proportion of maleness of the whole cuticle. Thus, the frequency of the structures being male is a reliable estimate of the real proportion of male cuticle. Portin (1977) analysed 42 regular gynandromorphs of Drosophila melanogaster from $A x^{E 2} / A x^{E 2} ; c a^{n d} / c a^{n d} \times y w^{e} A x^{E 2} s n^{3} / \Upsilon_{;}+1+$ flies, and in these the mean frequency of different structures being male 


\section{TABLE 2}

Frequency of each structure being male in the regular gynandromorphs induced by the claretnondisjunctional mutation ( $\mathrm{N}=366)$

\begin{tabular}{|c|c|c|}
\hline \multirow[b]{2}{*}{ Structure } & \multicolumn{2}{|c|}{ Frequency of being male } \\
\hline & $\mathcal{N}$ & $\%$ \\
\hline Palpus & $171 \cdot 0$ & $46 \cdot 72$ \\
\hline Antenna & $171 \cdot 5$ & $46 \cdot 86$ \\
\hline Proboscis & $173 \cdot 0$ & 47.27 \\
\hline Vibrissa & $167 \cdot 0$ & $45 \cdot 63$ \\
\hline Vertical bristles & $162 \cdot 0$ & $44 \cdot 26$ \\
\hline Orbital bristles & $166 \cdot 0$ & $45 \cdot 36$ \\
\hline Ocellar bristles & $165 \cdot 0$ & $45 \cdot 08$ \\
\hline Post verticle bristle & $163 \cdot 0$ & $44 \cdot 54$ \\
\hline Humerus & $155 \cdot 5$ & $42 \cdot 49$ \\
\hline Presutural bristle & $169 \cdot 0$ & $46 \cdot 17$ \\
\hline Notopleural bristles & $168 \cdot 5$ & $46 \cdot 04$ \\
\hline Supra-alar bristle & $175 \cdot 0$ & $47 \cdot 81$ \\
\hline Dorsocentral bristles & $172 \cdot 5$ & $47 \cdot 13$ \\
\hline Scutellar bristles & $165 \cdot 0$ & $45 \cdot 08$ \\
\hline Wing & $161 \cdot 5$ & $44 \cdot 13$ \\
\hline Sternopleural bristles & $158 \cdot 0$ & $43 \cdot 17$ \\
\hline First leg & $149 \cdot 5$ & $40 \cdot 85$ \\
\hline Second leg & $147 \cdot 5$ & $40 \cdot 30$ \\
\hline Third leg & 155.5 & $42 \cdot 48$ \\
\hline Second tergite & $127 \cdot 0$ & $34 \cdot 70$ \\
\hline Second sternite & $131 \cdot 5$ & 35.93 \\
\hline Third tergite & $138 \cdot 0$ & $37 \cdot 70$ \\
\hline Third sternite & $133 \cdot 0$ & $36 \cdot 34$ \\
\hline Fourth tergite & $139 \cdot 5$ & 38.11 \\
\hline Fourth sternite & $135 \cdot 0$ & $36 \cdot 89$ \\
\hline Fifth tergite & $139 \cdot 5$ & $38 \cdot 11$ \\
\hline Fifth sternite & $128 \cdot 5$ & $35 \cdot 11$ \\
\hline Sixth tergite & $138 \cdot 5$ & $37 \cdot 84$ \\
\hline Sixth sternite & $127 \cdot 0$ & $34 \cdot 70$ \\
\hline Genitalia & 148.5 & $40 \cdot 57$ \\
\hline Mean & $153 \cdot 4$ & $41 \cdot 91$ \\
\hline Standard deviation & $15 \cdot 9$ & $4 \cdot 35$ \\
\hline
\end{tabular}

was 45.7 per cent. Garcia-Bellido and Merriam (1969) analysed 379 regular claret-induced gynandromorphs of $D$. simulans, first described by Sturtevant, and found the mean frequency of maleness was 44.8 per cent.

In table 3 the distribution of the 183 gynandromorphs according to the number of male parts is shown. Measured in this way, the mean proportion of maleness was $42 \cdot 40 \pm$ S.D. 21.48 per cent. Thus this method of measurement of the proportion of male cuticle is consistent with the two other methods. Sturtevant (1929) presented a corresponding distribution of 96 $D$. simulans gynandromorphs, and in the gynandromorphs of his table 6 the proportion of maleness was $38 \cdot 03 \pm$ S.D. 25.08 per cent.

It can be concluded that the mean proportion of male cuticle in Drosophila melanogaster gynandromorphs induced with the claret-nondisjunctional mutation in this study is about 42 per cent with a standard deviation of about 22 per cent. The data for $D$. simulans claret-induced gynandromorphs are comparable. 
TABLE 3

Number of male parts in gynandromorphs

\begin{tabular}{|c|c|c|c|}
\hline $\begin{array}{l}\text { Number } \\
\text { of parts }\end{array}$ & $\begin{array}{c}\text { Number } \\
\text { of specimens }\end{array}$ & $\begin{array}{l}\text { Number } \\
\text { of parts }\end{array}$ & $\begin{array}{c}\text { Number } \\
\text { of specimens }\end{array}$ \\
\hline 1 & 2 & 31 & 4 \\
\hline 2 & 0 & 32 & 3 \\
\hline 3 & 1 & 33 & 6 \\
\hline 4 & 3 & 34 & 5 \\
\hline 5 & 0 & 35 & 2 \\
\hline 6 & 5 & 36 & 3 \\
\hline 7 & I & 37 & 4 \\
\hline 8 & 4 & 38 & 4 \\
\hline 9 & 5 & 39 & 3 \\
\hline 10 & 5 & 40 & 2 \\
\hline 11 & 3 & 41 & 4 \\
\hline 12 & 5 & 42 & 2 \\
\hline 13 & 5 & 43 & 2 \\
\hline 14 & 4 & 44 & 1 \\
\hline 15 & 0 & 45 & 1 \\
\hline 16 & 7 & 46 & 1 \\
\hline 17 & 0 & 47 & 0 \\
\hline 18 & 4 & 48 & 1 \\
\hline 19 & 4 & 49 & 0 \\
\hline 20 & 2 & 50 & 0 \\
\hline 21 & 10 & 51 & 1 \\
\hline 22 & 7 & 52 & 0 \\
\hline 23 & 11 & 53 & 0 \\
\hline 24 & 1 & 54 & 1 \\
\hline 25 & 7 & 55 & 0 \\
\hline 26 & 5 & 56 & 1 \\
\hline 27 & 5 & 57 & 0 \\
\hline 28 & 6 & 58 & 1 \\
\hline 29 & 5 & 59 & 3 \\
\hline \multirow[t]{3}{*}{30} & 9 & 60 & 2 \\
\hline & Mean 25.44 parts & $\begin{array}{l}\text { Total } \\
42.40 \%\end{array}$ & 183 \\
\hline & 12.89 parts & $21.48 \%$ & \\
\hline
\end{tabular}

(ii) Fourth chromosome mosaicism in the gynandromorphs

Ninety-four gynandromorphs from the second cross were inspected for haplo- 4 mosaicism. A total of 20 specimens were found to be so. Thus 21.28 per cent of the regular gynandromorphs were found to be haplo-4 mosaics also. This figure is consistent with the observation of Hinton (published by Davis, 1969) that 17.78 per cent of 388 Drosophila melanogaster $c a^{n d}$-induced gynandromorphs were haplo- 4 mosaics. The data for $D$. simulans claret-induced gynandromorphs are similar: in Sturtevant's (1929) material 19.62 per cent of the gynandromorphs were haplo-4 mosaics. Haplo-4 mosaics occur far too frequently to be consistent with independent loss. D. melanogaster gynandromorphs have a 4- to 5-fold greater chance of being mosaic for the 4 th chromosome than do non-gynanderic individuals (Davis, 1969; Hall et al., 1976). It is also known that among haplo-4 mosaic gynandromorphs of $D$. simulans three-quarters had lost the $\mathrm{X}$ and 4 th chromosome in the same mitotic cleavage and from the same daughter nucleus (Sturtevant, 1929). 
In table 4 the distribution of the haplo- 4 mosaic gynandromorphs is shown according to the 4th chromosome constitution, and compared with the respective data for $D$. simulans. It appears that, as in $D$. simulans, approximately three-quarters of the haplo- 4 mosaics in $D$. melanogaster had lost the 4th chromosome and the $\mathrm{X}$ chromosome in the same mitosis and

\section{TABLE 4}

Distribution of regular ginandromorphs which were 4 th chromosome mosaics according to the 4th chromosome constitution. Gynandromorphs were induced with the claret-nondisjunctional mutation in Drosophila melanogaster, and with the claret mutation in Drosophila simulans

$\begin{array}{ccc}\text { 4th chromosome constitution } & \text { Drosophila } \\ \text { female part/male part } & \begin{array}{c}\text { Drosophila } \\ \text { melanogaster }\end{array} & \begin{array}{c}\text { simulans } \\ \mathbf{s}^{2}\end{array} \\ \text { not Minute/Minute } & 14 & 21 \\ \text { Minute/not Minute } & 1 & 0 \\ \text { not Minute/mosaic } & 3 & 4 \\ \text { mosaic/not Minute } & 2 & 2 \\ \text { Total } & 20 & 27\end{array}$

\footnotetext{
${ }^{1}$ Haplo-4 tissue has a Minute phenotype, whereas diplo-4 and triplo-4 tissues are not Minute.

${ }^{2}$ Data from Sturtevant (1929).
}

from the same daughter nucleus. Only one specimen was found which had lost the 4th chromosome in the same division but from a different nucleus than $\mathrm{X}$ chromosome loss. Of the haplo-4 mosaic gynandromorphs a quarter had lost the 4th chromosome in a different division than the $\mathrm{X}$ chromosome. In these cases the loss of the 4th chromosome appears to be independent of the loss of the $\mathrm{X}$ chromosome in both $D$. melanogaster, and $D$. simulans; i.e. the 4 th chromosome seems to be lost equally frequently both in the $\mathrm{XX}$ and the $\mathrm{XO}$ cell line.

\section{(iii) Female meiosis in gynandromorphs}

In Drosophila female and male meioses differ in many basic features, e.g. crossing-over is absent in males. Gynandromorphs from the first cross were randomly collected in a culture bottle. Some of them laid eggs. The female tissue of these gynandromorphs was heterozygous y w sn $3 /+++$, and they had mated with their $+++/ \gamma$ brothers. These gynandromorphs yielded a total of 145 offsprings. Of these 69 were males, of which eight were $y w$, and eight were $s n$. Thus, the crossing-over frequency between white and singed (23.19 per cent) is consistent with the standard value (about 19.5 per cent). Despite the few data, it can be concluded that crossing-over, and obviously the whole control of female meiosis is autonomous. This is in agreement with Lieb's (1971) observation that recombination rate in the $a 1 b c$ region of the second chromosome was normal in $R(1) w^{v C}$ induced gynandromorphs having female genitalia.

\section{Discussion}

\section{(i) An approach to the timing of $X$ chromosome loss during cleavage divisions}

The mean proportion of male cuticle, 41.67 per cent, in the gynandromorphs indicates that the mean time of maternal $\mathrm{X}$ chromosome loss is between first and second cleavage mitoses. 
The large variation in the proportion of male cuticle (S.D. $=22 \cdot \bar{\jmath} 1$ per cent) has two causes. Firstly, less than 20 per cent of the cells of the blastoderm will give rise to adult external tissues, whereas more than 80 per cent develop to adult internal tissues and larval tissues (Hall et al., 1976). Thus, the cuticle represents a small sample of cells of the blastoderm, and therefore a large variation in the proportion of male cuticle is to be expected. Secondly, gynandromorphs arise as consequences of maternal $\mathrm{X}$ chromosome loss in different cleavage mitoses. A loss in the first division usually causes a $50: 50$ distribution of XX and XO cells in the blastoderm. A loss in the second division results in 25 per cent of the blastoderm cells being $\mathrm{XO}$, and so on. It is also possible that loss occurs in more than one division. For example a loss in the first and in the second division causes three of the first four nuclei to be XO.

\section{TABLE 5}

The comparison of the observed distribution of the gynandromorphs according to the proportion of male cuticle with the corresponding normal distribution

\begin{tabular}{cccc} 
Proportion of & \multicolumn{3}{c}{ Number of gynandromorphs } \\
\cline { 2 - 4 } male cuticle (\%) & Observed & Expected & Difference \\
$0-20$ & 32 & 30.32 & 1.68 \\
$21-40$ & 59 & 55.92 & 3.08 \\
$41-60$ & 58 & 59.49 & 1.49 \\
$61-80$ & 22 & 29.59 & 7.59 \\
$81-100$ & 12 & 7.67 & 4.33 \\
& & & \\
Total & 183 & 183.00 & 18.17 \\
& & & \\
Mean \% & 41.58 & 41.58 & \\
S.D. \% & 22.22 & 22.22 & \\
& & &
\end{tabular}

Significance of the difference $x_{3}{ }^{2}=4.69 \quad P>0.1$

It can be concluded that if multiple loss of the $\mathrm{X}$ chromosome occurs, loss in the second and later divisions, following a loss in the first division, is much more infrequent than an initial loss in the second or later division. Let $x$ be the frequency of loss in the first division, $y$ the frequency of loss in the second division, and $z$ the frequency of loss in both first and second division. The mean proportion of male tissue in percentages per gynandromorph is thus $50 x+25 y+75 z$. If $y=z$, the mean will be 50 per cent. Since, however, it was observed that the mean was about 42 per cent, $z$ must be smaller than $y$. Likewise it can be shown that loss repeated in first, second, and third division must be more infrequent than an initial loss in the third division.

Although some gynandromorphs with very large XO patches occurred (table 3 ), it is probable that multiple losses are very infrequent or totally absent. If they occurred with a significant frequency, the distribution of the gynandromorphs according to the proportion of male cuticle would differ significantly from a normal distribution because of the excess of gynandromorphs with large male patches. In table 5, and in fig. 2 the observed distribution of the gynandromorphs has been compared with a normal distribution which had the same mean and standard deviation as 


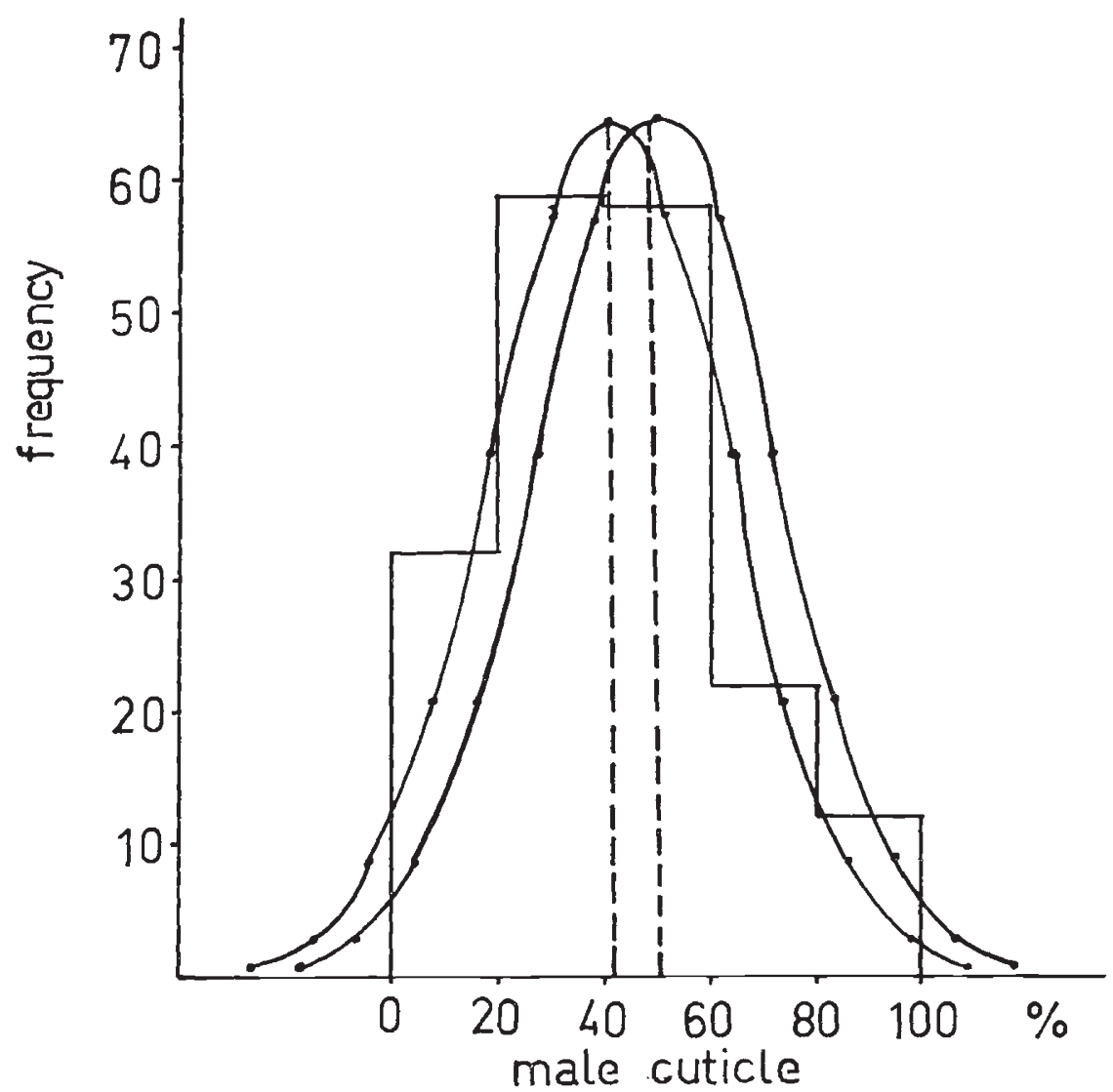

FIG. 2.-Observed distribution of gynandromorphs according to the proportion of male cuticle compared with the corresponding normal distribution (mean and S.D. $=41.58 \pm 22.22$ per cent), and with the normal distribution expected on the assumption of loss of the $\mathrm{X}$ chromosome in the first mitotic cleavage only (mean and S.D. $=50 \cdot 00 \pm 22 \cdot 51$ per cent $)$.

the observed. It appears that the observed distribution did not differ significantly from a normal distribution. Nor do the distribution of gynandromorphs from cross I or cross II tested separately differ significantly from a normal distribution.

The normal distribution of the gynandromorphs according to the amount of male cuticle suggests that the cuticle represents a random sample of the initial distribution of XX and XO cells. Furthermore it suggests, but does not prove, that multiple losses of the $\mathrm{X}$ chromosome do not occur, or are, in any case, infrequent.

The observed distribution of gynandromorphs was also compared with the theoretical normal distribution expected on the assumption of X chromosome loss in the first cleavage division only, i.e. the observed distribution was compared with a normal distribution with a mean of 50 per cent but with a same standard deviation as the observed distribution (table 6, fig. 2). A significant difference was observed $\left(\chi_{3}{ }^{2}=31.80 ; P<0.001\right)$. The sum of the absolute values of the differences was 61.77 (table 6). This 
TABLE 6

The comparison of the observed distribution of the ginandromorphs according to the proportion of male cuticle with the theoretical normal distribution expected on the assumption of first cleavage division loss of the maternal $X$ chromosome

\begin{tabular}{|c|c|c|c|}
\hline \multirow{2}{*}{$\begin{array}{c}\text { Proportion of } \\
\text { male cuticle }(\%)\end{array}$} & \multicolumn{3}{|c|}{ Number of gynandromorphs } \\
\hline & Observed & Expected & Difference \\
\hline $0-20$ & 32 & $16 \cdot 73$ & $15 \cdot 27$ \\
\hline $21-40$ & 59 & $43 \cdot 39$ & $15 \cdot 61$ \\
\hline $41-60$ & 58 & $62 \cdot 77$ & $4 \cdot 77$ \\
\hline $61-80$ & 22 & $43 \cdot 39$ & $21 \cdot 39$ \\
\hline $81-100$ & 12 & $16 \cdot 73$ & 4.73 \\
\hline Total & 183 & 183.00 & $61 \cdot 77$ \\
\hline Mean \% & $41 \cdot 67$ & $50 \cdot 00$ & \\
\hline S.D. $\%$ & $22 \cdot 51$ & $22 \cdot 51$ & \\
\hline
\end{tabular}

Significance of the difference $\chi_{3}{ }^{2}=31.80 \quad P<0.001$

suggests that approximately one-third $(61 \cdot 77 / 183)$ of the gynandromorphs apparently arose as a consequence of later than first division loss of the maternal X chromosome, and two-thirds arose as a consequence of the first division loss. This is supported by the fact that the excess of gynandromorphs in classes to the left from the central class in the distribution as compared to the classes to the right from the central class was $57=[(32-12)$ $+(59-22)]$. Assuming that no multiple losses of the $\mathrm{X}$ chromosome occurred, this represents the number of gynandromorphs which arose as a consequence of loss in a division later than first. This is also approximately one-third of the total number of gynandromorphs.

The simplest model for the timing of the maternal $\mathrm{X}$ chromosome loss during cleavage is to assume that no multiple losses occur, but two-thirds of the losses occur in the first cleavage mitosis, and one-third in the second. This would give an expected value of $\left(\frac{2}{3}\right) \times 50+\left(\frac{1}{3}\right) \times 25=41.67$ per cent for the mean of the proportion of the male tissue. This fits the observed value. However, it is not impossible that the frequency of loss may decrease gradually as the cleavage proceeds. Assuming that multiple losses do not occur, and that the frequencies of losses in subsequent cleavage mitoses are related as $3: 1: \frac{1}{3}: \frac{1}{9}: \ldots$, where the sum of the second and subsequent division losses is one-third of the total number of losses, the expected value for the mean proportion of male tissues in the gynandromorphs would be 40 per cent which does not differ significantly from the observed value either.

Assuming that no multiple losses of the X chromosome occur, it may be concluded, albeit the power of tests used is not very high, that approximately two-thirds of the losses occur in the first mitotic cleavage, and approximately one-third in later divisions. If multiple losses occur, the probability of a repeated loss at a given division is smaller than the frequency of the initial loss at that division.

\section{(ii) Correlation of the loss of $X$ and 4 th chromosomes}

Elimination of the 4th chromosome is highly correlated with the elimination of the $\mathrm{X}$ chromosome. Approximately three-quarters of the 
4th chromosome losses in the gynandromorphs were in the same division, and in the same daughter nucleus as the $\mathrm{X}$ chromosome loss. Approximately one-quarter of the losses of the 4th chromosome occurred in a different (apparently most often in a later) division than the loss of the $\mathrm{X}$ chromosome. In these latter cases the loss of the 4th chromosome appears not to be correlated with the loss of the $\mathrm{X}$ chromosome, i.e. the 4 th chromosome was lost approximately equally frequent in the XX and XO cell line. These facts are of importance in considering the causes of chromosome loss in the eggs of homozygous $c a^{n d}$ females.

Acknowledgments. - The technical assistance of Päivi Karihaara, Taina Lakkala, Christina Minn, Irma Pennanen, Johanna Renvall, and Jukka Vauramo in carrying out the second experiment is gratefully acknowledged. The author also wishes to thank most warmly Dr Yrjö Mäkinen for statistical advice, and Dr Aloha Alava for critical reading of the manuscript.

\section{REFERENGES}

BonNier, G., ANd TEdin, o. 1940. Biologisk variationsanalys. Bonnier, Stockholm.

DAVIS, D. G. 1969. Chromosome behavior under the influence of claret-nondisjunctional in Drosophila melanogaster. Genetics, 61, 577-594.

GARGia-Bellido, A., AND MERriam, J. R. 1969. Cell lineage of the imaginal discs in Drosophila gynandromorphs. 7. Exp. Zool., 170,61-76.

hall, J. G., Gelbart, w. M., AND KANkel, D. R. 1976. Mosaic systems. In The Genetics and Biology of Drosophila, eds. M. Ashburner and E. Novitski, vol. 1a, 264-314. Academic Press, London, New York, San Francisco.

LEWIS, E. B., AND GeNCARELla, w. 1952. Claret and nondisjunction in Drosophila melanogaster (Abstract). Genetics, 37, 600-601.

LIEB, E. 1971. Recombination in gynandromorphs of Drosophila melanogaster. Drosph. Inf. Serv., 46, 121 .

LINDSLEY, D. L., AND GRell, E. H. 1968. Genetic Variations of Drosophila melanogaster. Carnegie Institution of Washington Publication 627.

PORTIN, P. 1977. Analysis of the negative complementation of Abruptex alleles in gynandromorphs of Drosophila melanogaster. Genetics, 86, 309-319.

SNedecor, G. W., AND cochran, w. G. 1967. Statistical Methods (6th Ed.). The Iowa State College Press, Ames, lowa.

STURTEVANT, A. H. 1929. The claret mutant type of Drosophila simulans : a study of chromosome elimination and cell lineage. Z. Wiss. Zool., 135, 323-356. 